\title{
Factors Associated With Re-Intubation Within 14 Days After Ventilator Liberation
}

\author{
Chia-Chen Chu MSc RRT FAARC, Chin-Jung Liu RRT, Suh-May Yen MD PhD, \\ Wen-Yu Chou MHA, Pei-Tseng Kung ScD, Yuh-Show Tsai PhD, and Wen-Chen Tsai DrPH
}

\begin{abstract}
BACKGROUND: According to Taiwan's integrated delivery system policy, ventilator-dependent patients are successfully liberated from mechanical ventilation in accordance with step-down care. However, premature discharge affects the 14-d readmission quality index. Therefore, we explored the risk and related factors of subjects liberated from mechanical ventilation who were re-intubated within $14 \mathrm{~d}$. METHODS: This retrospective study analyzed a cohort of ventilator-dependent subjects $17 \mathrm{y}$ of age and older using a population-based database from the Taiwan National Health Research Institutes Database from 2006 to 2010. Chi-square test and logistic regression analyses were used to explore whether subjects liberated from mechanical ventilation were re-intubated within $\mathbf{1 4} \mathbf{d}$ and to investigate the related factors. RESULTS: A total of $\mathbf{1 5 , 8 4 0}$ ventilator-dependent subjects were liberated from mechanical ventilation, and 449 subjects were re-intubated within $14 \mathrm{~d}$; the total re-intubation rate was $\mathbf{2 . 8 3} \%$. The factors related to a higher risk of re-intubation were also the reasons for ventilator use, including complications, hospital accreditation level, and the ventilator weaning care stage. A higher risk of re-intubation was identified in subjects with COPD (odds ratio $[\mathrm{OR}] 1.32,95 \%$ CI 1.02-1.7, $P=.035$ ) or pneumonia $(\mathrm{OR} 1.4,95 \% \mathrm{CI} 1.07-1.86, P=.02)$ and in subjects who stayed at a district hospital (OR $3.53,95 \%$ CI $2.48-5.01, P<.001)$. Liberation from mechanical ventilation in the respiratory care ward and home respiratory care were associated with the highest risk of re-intubation, which was $\mathbf{2 . 3 2}$ times that of ICU subjects $(P<.001)$. CONCLUSIONS: Factors associated with re-intubation within $14 \mathrm{~d}$ after ventilator liberation are related to the level and quality of the care setting; thus, to prevent re-intubation, more attention should be paid to higher-risk ventilator-dependent subjects after they are liberated from mechanical ventilation. Key words: ventilator-dependent subject; re-intubation; integrated delivery system. [Respir Care 2017;62(12):1557-1564. () 2017 Daedalus Enterprises]
\end{abstract}

\section{Introduction}

Mechanical ventilation is required by $33-40 \%$ of patients admitted to ICUs. ${ }^{1,2}$ In the United States, patients

\footnotetext{
Dr Chu and Ms Liu are affiliated with the Department of Respiratory Therapy; Ms Liu, Ms Wen-Yu Chou, and Dr Tsai are affiliated with the Department of Health Services Administration; and Ms Liu and Dr Tsai are affiliated with Public Health, China Medical University, Taichung, Taiwan. Dr Yen is affiliated with the Department of Chinese Medicine, Nantou Hospital, Nantou, Taiwan. Mr Chu and Dr Tsai are affiliated with the Department of Biomedical Engineering, Chung-Yuan Christian University, Taoyuan City, Taiwan. Dr Kung is affiliated with the Department of Healthcare Administration, Asia University, Taichung, Taiwan.
}

Mr Chu presented a version of this paper at the American Association for Respiratory Care Congress 2015, held November 7-10, 2015, in Tampa, Florida. receiving mechanical ventilation for $\geq 21 \mathrm{~d}$ have been estimated to incur health-care costs of $\$ 423,596 /$ person an-

\footnotetext{
This study was supported by China Medical University, Asia University, Taiwan Department of Health Grants CMU103-ASIA-23 and DOH102NH-9009, and Taiwan Ministry of Health and Welfare Clinical Trial Center Grant MOHW106-TDU-B-212-113004. The authors have disclosed no conflicts of interest.
}

The first 2 authors contributed equally to this work.

Supplementary material related to this paper is available at http:// www.rcjournal.com.

Correspondence: Wen-Chen Tsai DrPH, China Medical University, 91 Hsueh-Shih Road, 40402 Taichung, Taiwan. E-mail: wtsai@mail.cmu.edu.tw.

DOI: $10.4187 /$ respcare. 05649 
nually. ${ }^{3}$ Zilberberg et $\mathrm{al}^{4}$ have projected that the number of patients in the United States requiring $\geq 4 \mathrm{~d}$ of mechanical ventilation will reach 605,898 in 2020 , more than double the number in 2005. Ventilator-dependent patients' longterm occupation of high-cost ICU beds imposes a heavy financial burden on the health-care system and can crowd out other patients in need of acute care. Transferring ventilator-dependent patients out of ICUs into long-term care facilities has been shown to be a more cost-effective approach. ${ }^{5-7}$

The majority of ventilator-dependent patients are male 8 and elderly,, 910 and whether a patient will be successfully liberated from mechanical ventilation has been associated with numerous factors, such as the patient's sex, ${ }^{11}$ age, ${ }^{12}$ and health status; ${ }^{12}$ the type or level of the treating healthcare organization ${ }^{13}$; and the reason for ventilator use. ${ }^{11}$ Patients with neuromuscular/chest wall conditions ${ }^{11}$ or more comorbid conditions, as well as older patients, ${ }^{12}$ were shown to have more difficulty weaning off ventilator use, whereas patients who were female, had COPD, ${ }^{11}$ or were being treated at a medical center ${ }^{13}$ were associated with successful liberation from mechanical ventilation. A study in the United States reported that the rate of successful liberation from mechanical ventilation was $50.3 \% .^{14}$

In Taiwan, as of April 2014, there were 12,521 patients with respiratory failure who required long-term mechanical ventilation, ${ }^{15}$ and that number is increasing annually. Respiratory failure accounted for $10.2 \%$ of Taiwan's total national health-care expenditure in $2013 .{ }^{16}$ Increasing the ventilator liberation rate of ventilator-dependent patients and decreasing the re-intubation rate are important indicators of health-care quality for acute/ICU care. In 2000, Taiwan launched an integrated delivery system with a prospective payment demonstration program for ventilatordependent patients. This program established a 4-stage respiratory care system for these patients based on the number of days receiving mechanical ventilation and their clinical stability. Mechanically ventilated patients with acute, unstable medical conditions are treated in an ICU for $1-21 \mathrm{~d}$ and then transferred from the ICU to a respiratory care center. After $63 \mathrm{~d}$ of ventilator use, $42 \mathrm{~d}$ of respiratory care center treatment, or a thoracic specialist's assessment that ventilator liberation is not achievable in the short term, patients are transferred to a respiratory care ward. After their conditions are stabilized, patients are transitioned to home respiratory care. This integrated delivery care system is intended to reduce ventilator-dependent patients' stay in ICUs, reduce health-care costs, and improve the quality of care.

Previous research has assessed some of the effects of Taiwan's integrated delivery care program. Among the findings, the average length of ICU stay has decreased from 34.4 to $30.5 \mathrm{~d}$; ventilator liberation rates in respiratory care centers and respiratory care wards have steadily

\section{QUICK LOOK}

\section{Current knowledge}

According to integrated delivery system policy, ventilator-dependent patients achieve successful liberation from mechanical ventilation in accordance with stepdown care, but premature discharge affects the 14-d readmission quality index. The factors leading to reintubation of ventilator-dependent patients following successful liberation from mechanical ventilation in accordance with step-down care have not been well described.

\section{What this paper contributes to our knowledge}

The factors related to risk of re-intubation in ventilatordependent subjects who were liberated from mechanical ventilator within $14 \mathrm{~d}$ were the reason for ventilator use, complications, hospital accreditation level, and the location of care. These factors might be used to determine the optimal time for liberation from mechanical ventilation and to prevent re-intubation through early intervention.

increased in successive years ${ }^{17}$; the mortality rate of ventilator-dependent patients in respiratory care centers has decreased; and total in-patient expenditures were significantly reduced..$^{18}$ In this study, we examined the relative risk and associated factors of re-intubation within $14 \mathrm{~d}$ after successful liberation from mechanical ventilation.

\section{Methods}

\section{Data Source and Study Subjects}

Secondary data (from January 1, 2006 to December 31, 2010) from the National Health Insurance Research Database, which is maintained by Taiwan's National Health Research Institutes, were used for a retrospective analysis of ventilator-dependent subjects $17 \mathrm{y}$ of age and older, who were successfully liberated from mechanical ventilation and then re-intubated within $14 \mathrm{~d}(N=15,840)$.

Ventilator-dependent subjects were defined as having received mechanical ventilation support for $\geq 21$ consecutive days and had not been discontinued long enough to meet the criteria for successful weaning. (According to the regulations of Taiwan's National Health Insurance Administration for claims payment, successful ventilator weaning is defined as discontinuation of mechanical ventilation for $\geq 5 \mathrm{~d}$, during which the patient is ventilatorindependent.) Ventilator-dependent subjects included those using invasive and noninvasive ventilation. 


\section{Factors Associated With Re-Intubation}

\section{Description of Variables}

The dependent variables analyzed were whether re-intubation was performed within $14 \mathrm{~d}$ after successful ventilator weaning. The independent variables analyzed included the subjects' personal characteristics (sex, age, and monthly salary), reasons for ventilator use, health status (Charlson comorbidity index and ventilator complications), characteristics of the health-care organization (level and ownership), and ventilator weaning care stage (ICU, respiratory care center, respiratory care ward, or home respiratory care).

The following additional information on the variables was obtained. (1) The reasons for ventilator use, as defined by the primary and secondary diagnosis codes, according to the International Classification of Diseases, Ninth Revision, Clinical Modification, at the initial use of mechanical ventilation, included pneumonia, septicemia, stroke, COPD, heart failure, trauma, coronary artery disease, lung cancer, and other diseases (eg, polio syndrome, spinal cord injury, muscular dystrophy, spinal lateral sclerosis, and multiple sclerosis). (2) The Charlson comorbidity index was used as a measure of comorbidity. ${ }^{19}$ The Charlson comorbidity index scores were categorized as $\leq 3,4-6$, $7-9$, or $\geq 10$, with a high score indicating high comorbidity severity. (3) Complications included pneumonia, pneumothorax, pulmonary edema, and other diseases (eg, laryngeal edema, subcutaneous emphysema, oxygen toxicity, and pulmonary embolism) that were recorded as the primary or secondary diagnosis for 2 out-patient visits or one hospitalization. (4) The characteristics of the health-care organization were the level and ownership of the healthcare organization where a subject's successful liberation from mechanical ventilation was observed, or where a subject who was not successfully liberated from mechanical ventilation last stayed as of the end of the observation period. (5) The ventilator weaning care stage was the level of care (eg, ICU, respiratory care center, respiratory care ward, or home respiratory care) at which a subject's successful weaning was observed, or at which a subject who was not successfully liberated from mechanical ventilation was last placed as of the end of the observation period. (6) Successful weaning was defined as the discontinuation of mechanical ventilation for $\geq 5 \mathrm{~d}$. (7) Re-intubation within $14 \mathrm{~d}$ after successful weaning was defined as reinstitution of mechanical ventilation within $14 \mathrm{~d}$ of successful weaning. (8) A low-income household designation was made if the subject belonged to a household in which the average per-person monthly income was $<60 \%$ of the median per-person disposable income in the household's local area in the previous year. ${ }^{20}$ This study was approved by the institutional review board of Yuan's General Hospital in southern Taiwan (approval 20130603C).

\section{Statistical Analysis}

This study applied the SAS 9.3 software suite (SAS Institute, Cary, North Carolina) for database processing and statistical analysis, used frequency distributions and percentages for describing various variable distributions, and employed the means and SD values to present the distributions of continuous variables.

First, the chi-square test was used to assess the association of re-intubation within $14 \mathrm{~d}$ of weaning with each independent variable. Next, logistic regression analysis was then performed to examine the risk and associated factors of re-intubation within $14 \mathrm{~d}$ of weaning in successfully weaned subjects. In this study, a $P<.05$ was considered to be statistically significant.

\section{Results}

\section{Subject Demographics}

There were 15,840 ventilator-dependent subjects who were $17 \mathrm{y}$ of age or older and had successful liberation from a mechanical ventilator from the National Health Research Institutes from January 1, 2006 to December 31, 2010, and whose records were obtained from National Health Research Institutes secondary database. These subjects were predominantly men $(58.5 \%$ males and $41.5 \%$ females) and primarily in the 65-84-y-old age group $(56.9 \%)$. The \$566-747 monthly salary group (40.3\%) represented the largest percentage of these subjects, followed by the $\$ 747-943$ monthly salary group (34.1\%). A total of 449 subjects were re-intubated within $14 \mathrm{~d}$ after being liberated from mechanical ventilation $(2.8 \%)$. This group had more men than women (60.4\% vs $39.6 \%)$, and most of the subjects were in the 65-84-y-old age group (60.6\%). The \$747-943 monthly salary group represented the largest percentage of these subjects $(41 \%)$, followed by the \$566-747 monthly salary group (34.3\%) (Table 1).

\section{Health-Care Organization Characteristics}

Based on the number and proportions of re-intubated subjects, the health-care organization level was ranked as follows: district hospital (39.2\%, 176 subjects), regional hospital (35.6\%, 160 subjects), and medical center (25.2\%, 113 subjects). Regarding hospital ownership, more of the subjects who were re-intubated within $14 \mathrm{~d}$ after being liberated from mechanical ventilation were treated at nonpublic hospitals than at public hospitals $(79.7 \%$ vs $20.3 \%)$. The most common clinical locations were ranked in the following order: respiratory care wards $(47 \%, 211$ subjects), respiratory care centers $(41.9 \%, 188$ subjects), and ICUs (11.1\%, 50 subjects) (see Table 1). 
Table 1. Demographic Characteristics and Clinical Location of Subjects

\begin{tabular}{|c|c|c|}
\hline \multirow[t]{2}{*}{ Variables } & \multirow{2}{*}{$\frac{\begin{array}{c}\text { Total } \\
(N=15,840)\end{array}}{n(\%)}$} & \multirow{2}{*}{$\begin{array}{c}\text { Re-Intubation } \\
\text { Within } 14 \mathrm{~d} \\
(n=449) \\
n(\%)\end{array}$} \\
\hline & & \\
\hline \multicolumn{3}{|l|}{ Sex } \\
\hline Female & $6,567(41.5)$ & $178(39.6)$ \\
\hline Male & $9,273(58.5)$ & $271(60.4)$ \\
\hline \multicolumn{3}{|l|}{ Age } \\
\hline$\leq 24$ & $224(1.4)$ & $4(0.9)$ \\
\hline $25-44$ & $968(6.1)$ & $14(3.1)$ \\
\hline $45-64$ & $3,400(21.5)$ & $71(15.8)$ \\
\hline $65-84$ & $9,016(56.9)$ & $272(60.6)$ \\
\hline$\geq 85$ & $2,232(14.1)$ & $88(19.6)$ \\
\hline \multicolumn{3}{|l|}{ Monthly salary (USD) } \\
\hline LIH & $509(3.2)$ & $16(3.6)$ \\
\hline$\leq 566$ & $616(3.9)$ & $15(3.3)$ \\
\hline $566-747$ & $6,381(40.3)$ & $154(34.3)$ \\
\hline $747-943$ & $5,401(34.1)$ & $184(41)$ \\
\hline $943-1,189$ & $880(5.6)$ & $14(3.1)$ \\
\hline $1,189-1,500$ & $888(5.6)$ & $22(4.9)$ \\
\hline $1,500-1,893$ & $445(2.8)$ & $20(4.5)$ \\
\hline$\geq 1,893$ & $720(4.5)$ & $24(5.3)$ \\
\hline \multicolumn{3}{|c|}{ Level of health-care organization } \\
\hline Medical center & $7,165(45.2)$ & $113(25.2)$ \\
\hline Regional hospital & $6,978(44.1)$ & $160(35.6)$ \\
\hline District hospital & $1,697(10.7)$ & $176(39.2)$ \\
\hline \multicolumn{3}{|c|}{ Ownership of organization } \\
\hline Public hospital & $3,714(23.4)$ & $91(20.3)$ \\
\hline Non-public hospital & $12,126(76.6)$ & 358 (79.7) \\
\hline \multicolumn{3}{|l|}{ Location of care } \\
\hline ICU & $3,639(23)$ & $50(11.1)$ \\
\hline $\mathrm{RCC}$ & $9,453(59.7)$ & 188 (41.9) \\
\hline RCW and HRC & $2,748(17.3)$ & $211(47)$ \\
\hline \multicolumn{3}{|c|}{$\begin{array}{l}\text { Subjects include those weaned from mechanical ventilation and re-intubated within } 14 \mathrm{~d} . \\
\text { LIH }=\text { low-income household } \\
\text { RCC = respiratory care center } \\
\text { RCW = respiratory care ward } \\
\text { HRC = home respiratory care }\end{array}$} \\
\hline
\end{tabular}

\section{Relevant Factors Influencing Re-Intubation}

This study used the chi-square test to determine whether the variables of subject demographics, health status, hospital characteristics, and type of care facility demonstrated statistically significant correlations $(P<.05)$ with the reintubation of subjects within $14 \mathrm{~d}$ after liberation from mechanical ventilation (Table 2).

Regarding the sex variable, the rate of re-intubation for male subjects was slightly higher than that for female subjects $(2.9 \%$ vs $2.7 \%)$. For the age variable, the rate of re-intubation was highest for the 85-y and older group (3.9\%), followed by that for the 65-84-y-old age group (3\%). The high-age groups showed increasing numbers of re-intubated subjects; thus, the rate of re-intubation was positively correlated with age. Regarding the monthly salary variable, the re-intubation rate was highest for the NT\$ $45,801-57,800$ group (4.5\%), followed by the NT $\$ 22,801-$ 28,800 group (3.4\%).

Subjects who had been placed on a ventilator due to COPD exhibited significantly higher re-intubation rates within 14 days after liberation from mechanical ventilation compared with other subjects $(P<.001)$. In terms of the severity of the subjects' comorbidities (measured using the Charlson comorbidity index), the re-intubation rate was the highest for the Charlson comorbidity index $\leq 3$ group (2.9\%), followed by the Charlson comorbidity index 4-6 group (2.6\%). Subjects who had ventilator complications due to pneumonia exhibited significantly higher rates of re-intubation within $14 \mathrm{~d}$ after liberation from mechanical ventilation than did the other subjects $(P<.001)$.

Regarding levels of health-care organization, district hospitals $(10.4 \%)$ had the highest re-intubation rates, followed by the regional hospitals $(2.3 \%)$. Concerning ownership, the re-intubation rate at non-public hospitals was higher than that at public hospitals ( $3 \%$ vs $2.5 \%$ ). Finally, regarding the location of care, the re-intubation rate was highest for the respiratory care wards $(7.7 \%)$, followed by the respiratory care centers $(2 \%)$ (see Table 2 ).

\section{Analysis of the Risks of Re-Intubation}

This study used logistic regression analysis to investigate the risks of re-intubation within $14 \mathrm{~d}$ after liberation from mechanical ventilation. Regarding age, we used the 24-y and younger age group as a reference and determined that the risk of re-intubation was highest in the 85-y and older group (odds ratio $[\mathrm{OR}]=1.5,95 \%$ CI $0.54-4.33$, $P=.43)$, followed by the $65-84-\mathrm{y}$-old group $(\mathrm{OR}=1.3$, 95\% CI $0.45-3.52, P=.66)$. Furthermore, male subjects exhibited a risk of re-intubation 1.1 times that of female subjects. Concerning the severity of comorbidity, the risk of re-intubation was the highest for the group with a Charlson comorbidity index score of 4-6, which was 1.1 times that of the group with a Charlson comorbidity index score of $\leqq 3$. Regarding monthly salaries, this study used the low-income household group as a reference and found that the risk of re-intubation was the highest in the $\$ 1,500$ 1,893 monthly salary group $(\mathrm{OR}=1.8,95 \%$ CI 0.89 $3.55, P>.99)$, followed by the $\geq \$ 1,893$ monthly salary group $(\mathrm{OR}=1.3,95 \% \mathrm{CI} 0.66-2.49, P=.47)$.

The subjects who use ventilator without any reason as the reference group; the primary cause of mechanical ventilation was COPD that was the only identified risk factor for re-intubation (OR 1.32, 95\% CI 1.02-1.7, $P=.035$ ). Regarding the health-care organization levels, the risk of re-intubation was the highest at district hospitals (ie, 3.5 times greater than the medical centers), followed by re- 


\section{Factors Associated With Re-Intubation}

Table 2. Key Factors Determining Whether Were Re-Intubated Within 14 Days After Weaning From Mechanical Ventilation

\begin{tabular}{|c|c|c|c|c|c|c|c|}
\hline \multirow{3}{*}{ Variables } & \multirow{3}{*}{$\begin{array}{c}\begin{array}{c}\text { Total } \\
(N=15,840)\end{array} \\
n(\%)\end{array}$} & \multicolumn{2}{|c|}{ Re-Intubation Within $14 \mathrm{~d}$} & \multirow{3}{*}{$P$} & \multirow{3}{*}{ Adjusted OR } & \multirow{3}{*}{$95 \% \mathrm{CI}$} & \multirow{3}{*}{$P$} \\
\hline & & $\begin{array}{c}\text { No } \\
(n=15,391)\end{array}$ & $\begin{array}{c}\text { Yes } \\
(n=449)\end{array}$ & & & & \\
\hline & & $n(\%)$ & $n(\%)$ & & & & \\
\hline Sex & & & & .46 & & & \\
\hline Female & $6,567(41.5)$ & $6,389(97.3)$ & $178(2.7)$ & & 1 & & \\
\hline Male & $9,273(58.5)$ & $9,002(97.1)$ & $271(2.9)$ & & 1.1 & $0.89-1.34$ & .40 \\
\hline Age, y & & & & $<.001$ & & & \\
\hline$\leq 24$ & $224(1.4)$ & $220(98.2)$ & $4(1.8)$ & & 1 & & \\
\hline $25-44$ & $968(6.1)$ & 954 (98.6) & $14(1.4)$ & & 0.8 & $0.26-2.58$ & .74 \\
\hline $45-64$ & $3,400(21.5)$ & $3,329(97.9)$ & $71(2.1)$ & & 1 & $0.35-2.82$ & .99 \\
\hline $65-84$ & $9,016(56.9)$ & $8,744(97)$ & $272(3)$ & & 1.3 & $0.45-3.52$ & .66 \\
\hline$\geq 85$ & $2,232(14.1)$ & $2,144(96.1)$ & 88 (3.9) & & 1.5 & $0.54-4.33$ & .43 \\
\hline Monthly salary, USD & & & & .003 & & & \\
\hline LIH & $509(3.2)$ & 493 (96.9) & $16(3.1)$ & & 1 & & \\
\hline$\leq 566$ & $616(3.9)$ & 601 (97.6) & $15(2.4)$ & & 1.0 & $0.49-2.12$ & .96 \\
\hline $566-747$ & $6,381(40.3)$ & $6,227(97.6)$ & $154(2.4)$ & & 0.9 & $0.52-1.54$ & .69 \\
\hline $747-943$ & $5,401(34.1)$ & $5,217(96.6)$ & $184(3.4)$ & & 1.2 & $0.72-2.11$ & .44 \\
\hline $943-1,189$ & $880(5.6)$ & $866(98.4)$ & $14(1.6)$ & & 0.6 & $0.29-1.29$ & .19 \\
\hline $1,189-1,500$ & $888(5.6)$ & $866(97.5)$ & $22(2.5)$ & & 1.0 & $0.52-1.99$ & .97 \\
\hline $1,500-1,893$ & $445(2.8)$ & $425(95.5)$ & $20(4.5)$ & & 1.8 & $0.89-3.55$ & .10 \\
\hline$\geq 1,893$ & $720(4.5)$ & $696(96.7)$ & $24(3.3)$ & & 1.3 & $0.66-2.49$ & .47 \\
\hline \multicolumn{8}{|l|}{ Reasons for ventilator use } \\
\hline Pneumonia & & & & .035 & & & \\
\hline No & $8,482(53.5)$ & $8,264(97.4)$ & $218(2.6)$ & & 1 & & \\
\hline Yes & $7,358(46.5)$ & $7,127(96.9)$ & $231(3.1)$ & & 0.9 & $0.71-1.13$ & .34 \\
\hline Septicemia & & & & .59 & & & \\
\hline No & $11,983(75.7)$ & $11,638(97.1)$ & $345(2.9)$ & & 1 & & \\
\hline Yes & $3,857(24.3)$ & $3,753(97.3)$ & $104(2.7)$ & & 1.0 & $0.76-1.22$ & .77 \\
\hline Stroke & & & & .52 & & & \\
\hline No & $12,849(81.1)$ & $12,479(97.1)$ & $370(2.9)$ & & 1 & & \\
\hline Yes & 2,991 (18.9) & $2,912(97.4)$ & $79(2.6)$ & & 1.1 & $0.86-1.47$ & .40 \\
\hline COPD & & & & $<.001$ & & & \\
\hline No & $13,968(88.2)$ & $13,611(97.4)$ & $357(2.6)$ & & 1 & & \\
\hline Yes & $1,872(11.8)$ & $1,780(95.1)$ & $92(4.9)$ & & 1.3 & $1.02-1.7$ & .035 \\
\hline Heart failure & & & & .004 & & & \\
\hline No & $14,246(89.9)$ & $13,861(97.3)$ & $385(2.7)$ & & 1 & & \\
\hline Yes & $1,594(10.1)$ & $1,530(96.0)$ & $64(4.0)$ & & 1.3 & $0.98-1.75$ & .07 \\
\hline Accident & & & & .038 & & & \\
\hline No & $14,273(90.1)$ & $13,855(97.1)$ & $418(2.9)$ & & 1 & & \\
\hline Yes & $1,567(9.9)$ & $1,536(98)$ & $31(2)$ & & 0.8 & $0.55-1.18$ & .26 \\
\hline Coronary artery disease & & & & .08 & & & \\
\hline No & $15,017(94.8)$ & $14,600(97.2)$ & $417(2.8)$ & & 1 & & \\
\hline Yes & $823(5.2)$ & $791(96.1)$ & $32(3.9)$ & & 1.4 & $0.94-2.03$ & .10 \\
\hline Lung cancer & & & & .43 & & & \\
\hline No & $15,571(98.3)$ & $15,127(97.1)$ & $444(2.9)$ & & 1 & & \\
\hline Yes & $269(1.7)$ & $264(98.1)$ & $5(1.9)$ & & 0.7 & $0.28-1.8$ & .47 \\
\hline Others & & & & .07 & & & \\
\hline No & $14,994(94.7)$ & $14,578(97.2)$ & $416(2.8)$ & & 1 & & \\
\hline Yes & $846(5.3)$ & $813(96.1)$ & $33(3.9)$ & & 1.3 & $0.88-1.88$ & .20 \\
\hline Charlson comorbidity index score & & & & .52 & & & \\
\hline$\leq 3$ & $14,142(89.3)$ & $13,734(97.1)$ & $408(2.9)$ & & 1 & & \\
\hline $4-6$ & $1,181(7.5)$ & $1,150(97.4)$ & $31(2.6)$ & & 1.1 & $0.72-1.59$ & .75 \\
\hline $7-9$ & $104(0.7)$ & $103(99)$ & $1(1)$ & & 0.5 & $0.06-3.45$ & .46 \\
\hline$\geq 10$ & $413(2.5)$ & $404(97.8)$ & $9(2.2)$ & & 1.1 & $0.51-2.18$ & .88 \\
\hline
\end{tabular}


Table 2. Continued

\begin{tabular}{|c|c|c|c|c|c|c|c|}
\hline \multirow{3}{*}{ Variables } & \multirow{3}{*}{$\begin{array}{c}\begin{array}{c}\text { Total } \\
(N=15,840)\end{array} \\
n(\%)\end{array}$} & \multicolumn{2}{|c|}{ Re-Intubation Within $14 \mathrm{~d}$} & \multirow{3}{*}{$P$} & \multirow{3}{*}{ Adjusted OR } & \multirow{3}{*}{$95 \% \mathrm{CI}$} & \multirow{3}{*}{$P$} \\
\hline & & \multirow{2}{*}{$\frac{\begin{array}{c}\text { No } \\
(n=15,391)\end{array}}{n(\%)}$} & \multirow{2}{*}{$\begin{array}{c}\begin{array}{c}\text { Yes } \\
(n=449)\end{array} \\
n(\%)\end{array}$} & & & & \\
\hline & & & & & & & \\
\hline \multicolumn{8}{|l|}{ Ventilator complications } \\
\hline Pneumonia & & & & $<.001$ & & & \\
\hline No & $5,198(32.8)$ & $5,099(98.1)$ & 99 (1.9) & & 1 & & \\
\hline Yes & $10,642(67.2)$ & $10,292(96.7)$ & $350(3.3)$ & & 1.4 & $1.07-1.86$ & .02 \\
\hline Pneumothorax & & & & .56 & & & \\
\hline No & $15,267(96.4)$ & $14,837(97.2)$ & $430(2.8)$ & & 1 & & \\
\hline Yes & $573(3.6)$ & $554(96.7)$ & $19(3.3)$ & & 1.2 & $0.74-1.95$ & .46 \\
\hline Pulmonary edema & & & & .61 & & & \\
\hline No & $15,370(97)$ & $14,932(97.2)$ & $438(2.8)$ & & 1 & & \\
\hline Yes & $470(3)$ & $459(97.7)$ & $11(2.3)$ & & 0.7 & $0.39-1.34$ & .30 \\
\hline Others & & & & .81 & & & \\
\hline No & $15,700(99.1)$ & $15,254(97.2)$ & $446(2.8)$ & & 1 & & \\
\hline Yes & $140(0.9)$ & 137 (97.9) & $3(2.1)$ & & 0.8 & $0.25-2.61$ & .72 \\
\hline Level of health-care organization & & & & $<.001$ & & & \\
\hline Medical center & $7,165(45.2)$ & $7,052(98.4)$ & $113(1.6)$ & & 1 & & \\
\hline Regional & $6,978(44.1)$ & $6,818(97.7)$ & $160(2.3)$ & & 1.2 & $0.96-1.59$ & .11 \\
\hline District & $1,697(10.7)$ & $1,521(89.6)$ & $176(10.4)$ & & 3.5 & $2.48-5.01$ & $<.001$ \\
\hline Ownership of organization & & & & .12 & & & \\
\hline Public & $3,714(23.4)$ & $3,623(97.5)$ & $91(2.5)$ & & 1 & & \\
\hline Non-public & $12,126(76.6)$ & $11,768(97)$ & $358(3)$ & & 1.2 & $0.95-1.55$ & .13 \\
\hline Location of care & & & & $<.001$ & & & \\
\hline ICU & $3,639(23)$ & $3,589(98.6)$ & $50(1.4)$ & & 1 & & \\
\hline $\mathrm{RCC}$ & $9,453(59.7)$ & $9,265(98)$ & $188(2)$ & & 1.3 & $0.93-1.81$ & .13 \\
\hline RCW and HRC & $2,748(17.3)$ & $2,537(92.3)$ & $211(7.7)$ & & 2.3 & $1.59-3.41$ & $<.001$ \\
\hline $\begin{array}{l}\mathrm{OR}=\text { odds ratio } \\
\mathrm{LIH}=\text { low-income household } \\
\mathrm{RCC}=\text { respiratory care center } \\
\mathrm{RCW}=\text { respiratory care ward } \\
\text { HRC }=\text { home respiratory care }\end{array}$ & & & & & & & \\
\hline
\end{tabular}

gional hospitals, where the risk of re-intubation was 1.2 times that of the medical centers. Regarding organization ownership, the risk of re-intubation at non-public hospitals was higher than that at public hospitals $(\mathrm{OR}=1.2,95 \% \mathrm{CI}$ $0.95-1.55, P=.13)$. Regarding the location of care, respiratory care wards exhibited the highest risk of re-intubation, which was 2.2 times that of ICUs, followed by respiratory care centers, which had a risk of re-intubation that was 1.3 times that of ICUs (see Table 2).

\section{Discussion}

Our analysis showed that the probability of successful ventilator weaning decreased with increases in subject age and the Charlson comorbidity index scores of the ventilator-dependent subjects (see Table 2). Older and sicker subjects tended to have greater deterioration of organ function and, thus, may be more difficult to wean from mechanical ventilation. This result is the same as that reported by Yang et $\mathrm{al}^{21}$ and Tu et $\mathrm{al}^{22}$ (71\% of subjects older than $64 \mathrm{y}$ vs $69.9 \pm 14.3 \%$ and $68.7 \pm 15.1 \%$ ) for a respiratory care center of a medical center in southern Taiwan. This study used a secondary database, so we can only use the comorbidity index to indirectly measure the patient's disease severity, whereas Yang et $\mathrm{al}^{21}$ and Tu et $\mathrm{al}^{22}$ measured the disease severity with the APACHE II score.

The re-intubation rate ranged from 3 to $19 \%$ (total 13\%) in an International Consensus Conference article $23-28$ and was $45.4 \%$ for the longer weaning group in the WIND study $^{29}$; most of these subjects received mechanical ventilation for $<21 \mathrm{~d}$, and re-intubation after successful liberation from mechanical ventilation was not defined.

For individual hospital respiratory care center subjects, previous studies have reported a $19 \%$ re-intubation rate within $14 \mathrm{~d}$ after ventilator liberation. ${ }^{22}$ In the present study, the re-intubation rates within $14 \mathrm{~d}$ for subjects liberated 


\section{Factors Associated With Re-Intubation}

from ventilator use were 1.37, 1.99, and $7.68 \%$ for ICUs, respiratory care centers and respiratory care wards, and home respiratory care, respectively. The managed care method for strengthening management models applied by the National Health Insurance Administration of the Ministry of Health and Welfare has achieved the expected medical quality improvements.

In the Epstein and Ciubotaru study, ${ }^{30}$ intubated subjects were treated within $72 \mathrm{~h}$ after extubation, and the mortality rate increased with prolonged re-intubation; therefore, reintubation within $14 \mathrm{~d}$ after successful liberation from mechanical ventilation presents a higher risk. The use of ventilators due to pneumonia complications is an important factor in re-intubation, which also demonstrated significance in this study (OR 1.4, 95\% CI 1.07-1.86, $P=.02$ ).

Criner $^{12}$ reported that COPD and pneumonia are possible reasons for long-term ventilator use. In this study, it was shown that COPD was associated with an increased risk of re-intubation after ventilator use.

We also found that subjects in regional hospitals and district hospitals were at higher risk of re-intubation within $14 \mathrm{~d}$ after successful liberation from mechanical ventilation than subjects at medical centers, which is likely related to the quality and experience of different hospital grades. Chiang et $\mathrm{al}^{13}$ have observed greater success among medical center subjects, which aligns with Criner's findings. ${ }^{12}$

In the list of persistent monitoring indicators for Taiwan hospitals, admitted patients discharged within $14 \mathrm{~d}$ due to the same disease or a related disease (ie, non-planned rehospitalization rate indicators) was an indicator of integrated acute care. ${ }^{31}$ Therefore, we propose that patients who undergo re-intubation within $14 \mathrm{~d}$ after successful liberation from mechanical ventilation should be returned to intensive care, because patients who undergo re-intubation after failed extubation have a poor prognosis, with a hospital mortality rate exceeding $30-40 \%$, although the reasons remain unclear. ${ }^{32}$ This finding reminds respiratory therapists to more closely monitor the condition of these 2 types of patients during and after the ventilator-dependent patient's ventilator liberation.

\section{Conclusions}

The risk and related factors of re-intubation in ventilator-dependent subjects $17 \mathrm{y}$ and older who were liberated from mechanical ventilation within the past $14 \mathrm{~d}$ include the reason for ventilator use, complications, hospital accreditation level, and the location of care. The above factors were related to the care setting level and quality; thus, higher risk patients should receive more attention and be assessed after being liberation from mechanical ventilation to prevent re-intubation.

\section{ACKNOWLEDGMENTS}

This study is based in part on data from the Taiwan National Health Insurance Research Database provided by the National Health Insurance Administration, Ministry of Health and Welfare, and managed by the National Health Research Institutes. The interpretation and conclusions contained herein do not represent those of the National Health Insurance Administration, Ministry of Health and Welfare, or National Health Research Institutes.

\section{REFERENCES}

1. Dasta JF, McLaughlin TP, Mody SH, Piech CT. Daily cost of an intensive care unit day: the contribution of mechanical ventilation. Crit Care Med 2005;33(6):1266-1271.

2. Esteban A, Anzueto A, Frutos F, Alía I, Brochard L, Stewart TE, et al. Characteristics and outcomes in adult patients receiving mechanical ventilation: a 28-day international study. JAMA 2002;287(3): 345-355.

3. Cox CE, Carson SS, Govert JA, Chelluri L, Sanders GD. An economic evaluation of prolonged mechanical ventilation. Crit Care Med 2007;35(8):1918-1927.

4. Zilberberg MD, de Wit M, Pirone JR, Shorr AF. Growth in adult prolonged acute mechanical ventilation: implications for healthcare delivery. Crit Care Med 2008;36(5):1451-1455.

5. Gracey DR, Hardy DC, Koenig GE. The chronic ventilator-dependent unit: a lower-cost alternative to intensive care. Mayo Clin Proc 2000;75(5):445-449.

6. Nevins ML, Epstein SK. Weaning from prolonged mechanical ventilation. Clin Chest Med 2001;22(1):13-33.

7. Seneff MG, Wagner D, Thompson D, Honeycutt C, Silver MR. The impact of long-term acute-care facilities on the outcome and cost of care for patients undergoing prolonged mechanical ventilation. Crit Care Med 2000;28(2):342-350.

8. Chen CH, Lin WC, Lee CH, Chen CZ, Chu YC, Chang HY. Determining factors for successful weaning of patients in a respiratory care center-a one-year experience. Thorac Med 2004;19(4):236242.

9. Chen YJ, Jacobs WJ, Quan SF, Figueredo AJ, Davis AH. Psychophysiological determinants of repeated ventilator weaning failure: an explanatory model. Am J Crit Care 2011;20(4):292-302.

10. Douglas SL, Daly BJ, Brennan PF, Gordon NH, Uthis P. Hospital readmission among long-term ventilator patients. Chest 2001;120(4): 1278-1286.

11. Pilcher DV, Bailey MJ, Treacher DF, Hamid S, Williams AJ, Davidson AC. Outcomes, cost and long term survival of patients referred to a regional weaning centre. Thorax 2005;60(3):187-192.

12. Criner G. Long-term ventilator-dependent patients: new facilities and new models of care: the American perspective. Rev Port Pneumol 2012;18(5):214-216.

13. Chiang LL, Wu CP, Wang LY, Wu YT. Functional status and quality of life in ventilator-dependent patients. Formosan J Phys Ther 2004; 29(1):40-47.

14. Modawal A, Candadai NP, Mandell KM, Moore ES, Hornung RW, Ho ML, Tsevat J. Weaning success among ventilator-dependent patients in a rehabilitation facility. Arch Phys Med Rehabil 2002;83(2): 154-157.

15. The National Health Insurance Administration. National Health Insurance Business Executive Report (updated 2014). http://www.nhi. gov.tw/resource/Webdata/26347_1_1030523\%20103\%E5\%B9\%B44\% E6\%9C\%88\%Е4\%BB\%BD\%E5\%85\%A8\%Е6\%B0\%91\%Е5\%81\% $\mathrm{A} 5 \% \mathrm{E} 5 \% \mathrm{BA} \% \mathrm{~B} 7 \% \mathrm{E} 4 \% \mathrm{BF} \% 9 \mathrm{D} \% \mathrm{E} 9 \% 9 \mathrm{~A} \% \mathrm{AA} \% \mathrm{E} 6 \% \mathrm{~A} \% \mathrm{AD} \%$ $\mathrm{E} 5 \% 8 \mathrm{~B} \% 99 \% \mathrm{E} 5 \% 9 \mathrm{~F} \% \mathrm{~B} 7 \% \mathrm{E} 8 \% \mathrm{~A} 1 \% 8 \mathrm{C} \% \mathrm{E} 5 \% \mathrm{~A} 0 \% \mathrm{~B} 1 \% \mathrm{E} 5 \% 91 \%$ 8A.pdf. Accessed September 8, 2017. 


\section{Factors Associated With Re-Intubation}

16. The Ministry of Health and Welfare. National Health Insurance Abstract and Statistical Analysis. https://www.nhi.gov.tw/english/Content_List. aspx $? \mathrm{n}=9468 \mathrm{~B} 10284915 \mathrm{E} 07 \&$ topn $=616 \mathrm{~B} 97 \mathrm{~F} 8 \mathrm{DF} 2 \mathrm{C} 3614$. Accessed September 8, 2017.

17. Ku SC, Yu CJ. The current status of health delivery system and quality of care for patients with long-term mechanical ventilation in Taiwan. Taiwan Crit Care Med 2010;11(1):25-31.

18. Liu CJ, Chu CC, Chen W, Cheng WE, Shih CM, Tsai YS, et al. Impact of Taiwan's integrated prospective payment program on prolonged mechanical ventilation: a 6-year nationwide study. Respir Care 2013;58(4):676-682.

19. Deyo RA, Cherkin DC, Ciol MA. Adapting a clinical comorbidity index for use with ICD-9-CM administrative databases. J Clin Epidemiol 1992;45(6):613-619.

20. The Ministry of Health and Welfare. Public Assistance Act. http:// law.moj.gov.tw/Eng/LawClass/LawAll.aspx?PCode=D0050078. Accessed September 8, 2017.

21. Yang PH, Hung JY, Yang CJ, Tsai JR, Wang TH, Lee JC. Successful weaning predictors in a respiratory care center in Taiwan. Kaohsiung J Med Sci 2008;24(2):85-91.

22. Tu ML, Tseng CW, Tsai YC, Wang CC, Tseng CC, Lin MC, et al. Reinstitution of mechanical ventilation within 14 days as a poor predictor in prolonged mechanical ventilation patients following successful weaning. ScientificWorldJournal 2012;2012:957126.

23. Esteban A, Frutos F, Tobin MJ, Alía I, Solsona JF, Valverdú I, et al. A comparison of four methods of weaning patients from mechanical ventilation: Spanish Lung Failure Collaborative Group. N Engl J Med 1995;332(6):345-350.

24. Vallverdú I, Calaf N, Subirana M, Net A, Benito S, Mancebo J. Clinical characteristics, respiratory functional parameters, and outcome of a two-hour T-piece trial in patients weaning from mechanical ventilation. Am J Respir Crit Care Med 1998;158(6):1855-1862.
25. Brochard L, Rauss A, Benito S, Conti G, Mancebo J, Rekik N, et al. Comparison of three methods of gradual withdrawal from ventilatory support during weaning from mechanical ventilation. Am J Respir Crit Care Med 1994;150(4):896-903.

26. Esteban A, Alía I, Tobin MJ, Gil A, Gordo F, Vallverdú I, et al. Effect of spontaneous breathing trial duration on outcome of attempts to discontinue mechanical ventilation: Spanish Lung Failure Collaborative Group. Am J Respir Crit Care Med 1999;159(2): 512-518.

27. Farias JA, Retta A, Alía I, Olazarri F, Esteban A, Golubicki A, et al. A comparison of two methods to perform a breathing trial before extubation in paediatric intensive care patients. Intensive Care Med 2001;27(10):1649-1654.

28. Esteban A, Alía I, Gordo F, Fernández R, Solsona JF, Vallverdú I, et al. Extubation outcome after spontaneous breathing trials with $\mathrm{T}$ tube or pressure support ventilation: the Spanish Lung Failure Collaborative Group. Am J Respir Crit Care Med 1997;156(2 Pt 1):459465.

29. Béduneau G, Pham T, Schortgen F, Piquilloud L, Zogheib E, Jonas $\mathrm{M}$, et al. Epidemiology of weaning outcome according to a new definition: the WIND study. Am J Respir Crit Care Med 2017; 195(6): 772-783.

30. Epstein SK, Ciubotaru RL, Wong JB. Effect of failed extubation on the outcome of mechanical ventilation. Chest 1997;112(1): 186-192.

31. Joint Commission of Taiwan. List of Persistent Monitoring Indicators for Taiwan Hospital. http://hlm.tzuchi.com.tw/qme/images/ stories/files/104_0624.pdf. Accessed September 8, 2017.

32. Epstein SK, Ciubotaru RL. Independent effects of etiology of failure and time to reintubation on outcome for patients failing extubation. Am J Respir Crit Care Med 1998;158(2):489-493. 